\title{
COMMENTARY
}

\section{A simple meningococcal sepsis prognostic score: focusing on the human animal}

\author{
Paula Holinski and Ari R Joffe* \\ See related research by Alves et al., http://ccforum.com/content/17/2/R68
}

\begin{abstract}
A simple cheap meningococcal sepsis prognostic score based on readily available, rapid, objective laboratory base excess and platelet count was developed and validated retrospectively. This BEP score should facilitate sepsis clinical trials, allowing study of the relevant human animal model.
\end{abstract}

A new meningococcal sepsis prognostic score is reported in a previous edition of Critical Care [1]. Meningococcal sepsis in the pediatric intensive care unit (PICU) is often rapidly progressive with significant morbidity and mortality. When complicated by purpura fulminans, children may have permanent sequelae, including limb amputations. Process of care improvements, including early resuscitation and antibiotics, have been associated with improved survival [2]. Nevertheless, despite promising animal experiments leading to many human sepsis trials, no drug has been shown to improve outcomes [3].

Many have examined prediction of outcome from meningococcal sepsis, resulting in variably complex scores. To facilitate risk stratification for clinical trials of novel therapies, and to identify patients at high risk for deterioration, a score based on simple, objective, readily available rapid and low cost variables would be ideal. Alves and colleagues [1] describe such a score. Using databases of prospectively collected data from ongoing studies of children referred to PICU at five European centers from 1996 to 2011, data from children with a clinical diagnosis of meningococcal sepsis were retrospectively reviewed. The BEP score ('base excess platelets' from the first recorded laboratory sample) was developed from 309 patients with complete information, validated on the remaining 623 patients, and replicated on 134

*Correspondence: ari.joffe@albertahealthservices.ca

Department of Pediatrics, University of Alberta, 3A3.07 Stollery Children's Hospital, 8440112 Street, Edmonton, Alberta, Canada, T6G 2B7 retrospective patients referred to the Children's Acute Transport Service. The remarkably simple BEP score predicted death, with area under the receiver operating characteristic curve (AUC) of 0.86 (95\% confidence interval 0.80 to 0.91 ), better than Glasgow Meningococcal Septicaemia Prognostic Score, and similar to Rotterdam and PRISM scores. The replication dataset AUC was 0.96 ( $95 \%$ confidence interval 0.90 to 0.99 ).

The strengths of BEP are its simplicity, based on a relatively large sample with overall mortality 51/623 (8.2\%). There are some limitations. First, the score is not accurate enough to apply to individual patient decisions, with a validation set AUC of 0.86 , sensitivity $72 \%$, specificity $82 \%$, and positive predictive value $23 \%$ (Table S1 in [1]). Second, the score should be prospectively validated in an independent large cohort referred to PICU over a shorter time period (this study occurred over 15 years) and not necessarily enrolled in other clinical studies (which may have introduced selection bias in this study). Third, it is unclear whether BEP performs better than clinical variables often used to include patients in sepsis trials, such as ventilation and volume-refractory septic shock treated with inotropes. Finally, whether BEP predicts morbidity, particularly limb amputations, is unknown.

The authors claim that 'previous clinical trials of specific novel therapies in meningococcal sepsis, targeting pathways of inflammation and coagulation such as recombinant bactericidal/permeability inducing protein (rBPI) and activated protein C (rhAPC), have failed for reasons which are not clear'; however, a main reason 'may have been a failure to select a study population in whom neither death nor survival was inevitable' [1]. We hypothesize that this is unlikely the reason for the disappointing results of these (and all other) sepsis clinical trials. In the rBPI trial, the placebo mortality was 9.9\%, with severe amputations in 7.4\% [4]. In the rhAPC trial, all patients had respiratory and cardiovascular organ dysfunction, a median of 4 (interquartile range 3 to 4) organ failures, and placebo mortality $17.1 \%$ [5]. It is more likely that the reason trials have failed is because animal models in sepsis do not model human sepsis, 
despite some superficial phenotypic similarities [6,7]. Animals, including humans, are complex biological systems; their nonlinear dynamics and responses are extremely sensitive to initial conditions [6-9]. Despite superficial physiologic and genetic similarity between species, it is simply not to be expected that responses to similar perturbations or disease will be relevantly similar [6-9]. This has been the experience in biomedical animal research in general, not just sepsis research $[6,7,10]$. Of interest, the genomic responses to different acute inflammatory stresses, including trauma, burns, endotoxemia, sepsis, ARDS, and infection, are highly similar in humans; however, these responses are not reproduced in mouse models [11]. Among genes changed significantly in humans in these diseases, 'the murine orthologs are close to random in matching their human counterparts' [11]. Lethal toxicity to bacterial lipopolysaccharide varies almost 10,000-fold in different species [12]. Of 120 essential human genes with mouse orthologs, 17 (22.5\%) were nonessential in mice, suggesting that it is possible that mouse models of a large number of human diseases will not yield sufficiently accurate information' [13]. The ENCODE project suggests that over $80 \%$ of the genome is functionally important for gene expression; it is likely there are 'critical sequence changes in the newly identified regulatory elements that drive functional differences between humans and other species' [14]. This may explain 'the specific organ biology [from lineagespecific gene expression switches] of various mammals' [15].

\section{Conclusion}

With further validation, the BEP score may be useful to stratify enrolment in human meningococcal sepsis trials. More research into human sepsis is required, and, we believe, not yet more sepsis research using the failed animal modeling paradigm.

\section{Abbreviations}

$A \cup C$, area under the receiver operating characteristic curve; BEP, base excess platelets; PICU, pediatric intensive care unit.

\section{Competing interests}

The authors declare that they have no competing interests.

Published: 31 July 2013

\section{References}

1. Alves AC, Wright VJ, Perumal K, Binder A, Carrol ED, Emonts M, de Groot R, Hazelzet J, Kuijpers T, Nadel S, Zenz W, Ramnarayan P, Levin M, Coin L, Inwald DP: A new scoring system derived from base excess and platelet count at presentation predicts mortality in paediatric meningococcal sepsis. Crit Care 2013, 17:R68.

2. Ninis N, Phillips C, Bailey L, Pollock Jl, Nadel S, Britto J, Maconochiel, Winrow A, Coen PG, Booy R, Levin M: The role of healthcare delivery in the outcome of meningococcal disease in children: case-control study of fatal and nonfatal cases. BMJ 2005, 330:1475-1478.

3. Dyson A, Singer M: Animal models of sepsis: why does preclinical efficacy fail to translate to the clinical setting. Crit Care Med 2009, 37(Suppl):S30-S37.

4. Levin M, Quint PA, Goldstein B, Barton P, Bradley JS, Shemie SD, Yeh T, Kim SS, Caffaro DP, Scannon PJ, Giroir BP: Recombinant bactericidal/permeabilityincreasing protein ( $\mathrm{rBPI} 21)$ as adjunctive treatment for children with severe meningococcal sepsis: a randomized trial. Lancet 2000, 356:961-967.

5. Nadel S, Goldstein B, Williams MD, Dalton H, Peters M, Macias WL, Abd-Allah SA, Levy H, Angle R, Wang D, Sundin DP, Giroir B: Drotrecogin alfa (activated) in children with severe sepsis: a multicenter phase III randomized controlled trial. Lancet 2007, 369:836-843.

6. Horrobin DF: Modern biomedical research: an internally self-consistent universe with little contact with medical reality? Nat Rev Drug Discovery 2003, 2:151-154.

7. Akhtar A: The costs of animal experiments. In Animals and Public Health. Houndmills, UK: Macmillan Publishers; 2012:132-167.

8. Van Regenmortel MHV: Reductionism and complexity in molecular biology. EMBO Reports 2004, 5:1016-1020.

9. West GB: The importance of quantitative systemic thinking in medicine. Lancet 2012, 379:1551-1559.

10. Knight A: The Costs and Benefits of Animal Experiments. Houndmills, UK: Macmillan Publishers; 2013.

11. Seok J, Warren S, Cuenca AG, Mindrinos MN, Baker HV, Xu W, Richards DR, McDonald-Smith GP, Gao H, Hennessy L, Finnerty CC, Lopez CM, Honari S, Moore EE, Minei JP, Cuschieri J, Bankey PE, Johnson JL, Sperry J, Nathens AB, Billiar TR, West MA, Geschke MG, Klein MB, Gamelli RL, Gibran NS, Brownstein BH, Miller-Graziano C, Calvano SE, Mason PH, et al:: Genomic responses in mouse models poorly mimic human inflammatory diseases. Proc Natl Acad SciUSA 2013, 110:3507-3512

12. Warren HW, Fitting C, Hoff E, Adib-Conquy M, Beasley-Topliffe L, Tesini B, Liang X, Valentine C, Hellman J, Hayden D, Cavaillon JM: Resilience to bacterial infection: difference between species could be due to proteins in serum. J Infect Dis 2010, 201:223-232.

13. Liao BY, Zhang J: Null mutations in human and mouse orthologs frequently result in different phenotypes. Proc Natl Acad Sci U S A 2008, 105:6987-6992.

14. Ecker JR, Bickmore WA, Barroso I, Pritchard JK, Gilad Y, Segal E: Forum: Genomics. ENCODE explained. Nature 2012, 489:52-55.

15. Brawand D, Soumillon M, Necsulea A, Julien P, Csardi G, Harrigan P, Weier M, Liechti A, Aximu-Petri A, Kircher M, Alberta FW, Zeller U, Khaitovich P, Grutzner F, Bergmann S, Nielsen R, Paabo S, Kaessmann H: The evolution of gene expression levels in mammalian organs. Nature 2011, 478:343-348.

doi:10.1186/cc12766

Cite this article as: Holinski P, Joffe AR: A simple meningococcal sepsis prognostic score: focusing on the human animal. Critical Care 2013, 17:172. 